www.jmscr.igmpublication.org

Index Copernicus Value: 79.54

ISSN (e)-2347-176x ISSN (p) 2455-0450

crossrefDOI: https://dx.doi.org/10.18535/jmscr/v7i3.144

Journal Of Medical Science And Clinical Research

IGM Publication

An Official Publication of IGM Publication

\title{
Single injection thoracic paravertebral block for mastectomy operation: a comparative study between ropivacaine and bupivacaine
}

\section{Authors \\ Dr Neetika Mishra M.D. ${ }^{1}$, Dr Santanu Ghosh M.D. ${ }^{2^{*}}$, Dr Samit Kumar Khutia M.D. ${ }^{3}$, Dr Richeek Kumar Pal M.D. ${ }^{4}$, Dr Ahito Kibami M.B.B.S. ${ }^{5}$}

${ }^{1}$ Associate Professor, Dept. of Anesthesiology, North Bengal Medical College, Darjeeling, West Bengal

${ }^{2}$ Assistant Professor, Dept. of Anesthesiology, North Bengal Medical College,Darjeeling, West Bengal

${ }^{3}$ Consultant Anesthesiologist, Paramount Hospital Pvt. Ltd. Siliguri, West Bengal

${ }^{4}$ Assistant Professor, Dept. of Anesthesiology, North Bengal Medical College,Darjeeling, West Bengal

${ }^{5}$ Post Graduate Trainee, Dept. of Anesthesiology, North Bengal Medical College,Darjeeling, West Bengal

*Corresponding Author

\section{Dr Santanu Ghosh M.D.}

Assistant Professor, Dept. of Anesthesiology, North Bengal Medical College, Darjeeling, West Bengal

INDIA

\section{Abstract}

In recent years, regional anaesthetic techniques are being preferred as an adjuvant to general anaesthesia for the relief of postoperative pain. Breast surgeries are widely performed for cosmetic as well as oncological reasons and are associated with severe pain, PONV and respiratory complications due to inadequate pain relief. The present study was carried out to compare the efficacy of bupivacaine and ropivacaine in a single injection paravertebral block for controlling the postoperative pain after an elective breast surgeries.

Method: Seventy-two female patients scheduled for elective breast surgery were randomized into two groups; $R$ (Ropivacaine group) and B (bupivacaine group), 36 patients were allotted to each group. Both the groups received single injection paravertebral block with either of the drug. Surgery was conducted under general anaesthesia in both the groups. Intensity of postoperative pain was measured by VAS score at 2, 4, 6, 9, 12, 18 and 24 hrs. Intensity of pain and the analgesic consumption over the past 24 hours were recorded. Duration of postoperative analgesia was calculated by the time of first analgesic requirement.

Results: VAS scores in the immediate postoperative period that is 2-12 hrs. were comparable between both the groups ( $p>0.05)$, however the VAS score at 9,18 and 24 hours were significantly higher in group $R$. Fentanyl consumption in the first 24 hours was $68.06 \pm 23.612 \mu \mathrm{g}$ for the group $R$ as compared to $76.39 \pm 17.87 \mu \mathrm{g}$ for the group B which is statistically insignificant. The time to request for 1st analgesic was $646.56 \pm 115.85 \mathrm{~min}$ in the group $R$ and $609.25 \pm 75.02 \mathrm{mins}$ in the group $B(p>0.05)$ which is also statistically insignificant.

Conclusion: Ropivacaine and Bupivacaine both provide good quality of analgesia after single injection thoracic paravertebral block in breast surgeries.

Keywords: Ropivacaine, Bupivacaine, Paravertebral block, postoperative analgesia. 


\section{Introduction}

Nearly $40 \%$ of major breast cancer surgery patients experience significantly acute postoperative pain with a pain score above five reflecting inadequacy of conventional pain management. ${ }^{1}$ Acute pain if not controlled adequately, leads to chronic pain which has been reported by $50 \%$ patients suffering from moderate to severe impairment of daily lives. ${ }^{2,3}$ Many techniques have been tried so far to control this acute pain, regional analgesia appears to be very effective. Both thoracic epidural and thoracic paravertebral blocks (TPVB) have been shown to be highly effective in controlling this pain. While thoracic epidural provides effective intraoperative and postoperative analgesia, it is associated with risks of dural puncture, postural hypotension, urinary retention and neurologic damage. Compared to thoracic epidural, thoracic paravertebral block is reported to produce greater preservation of lung function and fewer adverse effects in post-thoracotomy patients. However, a lot of controversies exist regarding superiority of single injection versus multiple injections technique of TPVB and the clinical effects like contralateral segmental spread, failure rate, ipsilateral spinal nerve involvement and variation in duration of analgesia. These have created a lot of disagreement and speculations. Various local anaesthetics have already been used in TPVB for breast surgery. ${ }^{4-7}$ Bupivacaine remains to be the most frequently used local anaesthetic according to published studies. Ropivacaine is a new local anesthetic that could be a useful alternative to bupivacaine for TPVB. It has lower central nervous system and cardiac toxicity, and a less frequent incidence of unintended motor block (differential block) than bupivacaine. Moreover, there are a few clinical trials known to us that compared bupivacaine and ropivacaine given in paravertebral space as an adjunct to postoperative analgesia. Hence the present study has been designed to compare ropivacaine with bupivacaine for TPVB in respect to onset and duration of block.

\section{Materials and Methods}

The prospective randomised double blinded active controlled study was conducted after getting approval from the Hospital Ethics Committee. Female patients aged between 30-64 years, ASA I or II, scheduled for elective unilateral breast surgery with or without axillary lymph node dissection were included in the study. Patients with a present history of bleeding disorders and coagulopathy, allergy to amide-type local anaesthetics or any other significant co-morbid conditions were excluded from the study. Local infection or any space-occupying lesion at the site of the block or at the paravertebral space, severe scoliosis or other severe vertebral anomaly or chest wall deformities were among the other exclusion criteria. Considering a 30\% difference in the requirement of postoperative analgesics to be clinically relevant from previous studies and pilot study, with a power of $80 \%(\beta=0.2)$ at 0.05 level of significance $(\alpha=0.05)$, the required sample size is 30 patients for each group. So, 36 patients were taken in each group considering possibility of dropouts of about 20\%. The patients were randomly allocated into two groups to receive TPVB either with ropivacaine (group $\mathrm{R}, \mathrm{n}=36$ ) or bupivacaine (group $\mathrm{B}, \mathrm{n}=36$ ). The computer generated random numbers were kept in sealed opaque envelope for allocation concealment.

During preoperative visit on the day before surgery, patients were thoroughly explained about the procedure, the associated risks and benefits in their language before obtaining a written consent. They were made well conversant with the visual analogue scale (VAS) for postoperative pain assessment.

On arrival to the operation theatre (OT) complex, patients were taken to a monitored block room, adjacent to the main operation theatre room, where the paravertebral blocks (PVB) would be performed. Intravenous cannulation was done with $18 \mathrm{G}$ intravenous (iv) cannula and infusion of lactated Ringer's solution as maintenance fluid was started. Baseline vital parameters were noted. Patients were given incremental doses of iv 
midazolam (0.04-0.06 mg/kg) before block placement to decrease anxiety and discomfort during the procedure while maintaining a meaningful verbal patient contact. The patients of both the groups underwent paravertebral blocks at a single level (T4) using the classic loss-ofresistance to saline technique. The procedures were performed by two experienced staff anaesthesiologists, who were not involved in the study assessment. The patients were placed in lateral position with the side to be blocked upward. First, the predominance of $\mathrm{C} 7$ spinous process and the angles of the scapulae (corresponding to $\mathrm{T} 7$ spinous process) were identified. Next, the upper border of the spinous process of T3 vertebrae was marked. The site of needle introduction was marked at about $2.5 \mathrm{~cm}$ laterally from the midline of the upper border of the T3 vertebra. After taking proper aseptic measures, the skin and subcutaneous tissue at the point of needle insertion was infiltrated with $2 \mathrm{ml}$ of $1 \%$ lignocaine using a $25 \mathrm{G} 2.5 \mathrm{~cm}$ needle. An $18 \mathrm{G}$ tuohy needle was then inserted perpendicular to the skin to contact transverse process of the vertebra below (T4) at a variable depth $(2-4 \mathrm{~cm})$ from the skin depending on the build of the individual. After locating the transverse process the needle was then withdrawn up to the subcutaneous tissue and redirected in a caudal direction to walk off the lower aspect of the transverse process and gradually advanced directing slightly medially until a loss of resistance to saline, or a subtle pop of is felt. After the test dose, $15 \mathrm{ml}$ of local anaesthetic either ropivacaine $0.5 \%$ (Group $\mathrm{R}$ ) or bupivacaine $0.5 \%$ (Group B) were injected in small aliquots of 2$5 \mathrm{ml}$. The onset of sensory block was assessed at $5 \mathrm{~min}$ and every $5 \mathrm{~min}$ thereafter upto $30 \mathrm{~min}$. The block was considered successful if following criteria were met:

1. Onset of pinprick discrimination started within $15 \mathrm{~min}$,

2. Sensory block (T2-T6) achieved within a maximum time of $30 \mathrm{~min}$,
In case of block failure (when the above mentioned criteria were not met), the patients received general anaesthesia with other modes of analgesia and were excluded from the study. After the confirmation of successful block the patients were shifted to OT table and standard ASA monitors were attached before giving general anaesthesia. The patients were given fentanyl 2 $\mu \mathrm{g} / \mathrm{kg}$ iv. The induction of general anaesthesia was done with propofol $2 \mathrm{mg} / \mathrm{kg}$ iv and endotracheal intubation was facilitated with $0.6 \mathrm{mg} / \mathrm{kg}$ rocuronium. Tube position was confirmed with capnography. Anaesthesia was maintained by nitrous oxide (66\%) and oxygen (33\%) and intermittent isoflurane $0.5-1 \%$. The patients received top-ups of iv rocuronium $(0.1 \mathrm{mg} / \mathrm{kg})$ at regular intervals and iv fentanyl $(1 \mu \mathrm{g} / \mathrm{kg})$ at 1 hour interval if surgery extended beyond 1 hour. Heart rate and MAP were maintained within $20 \%$ of the baseline values by giving additional bolus doses of fentanyl $25 \mu \mathrm{g}$ and propofol $10 \mathrm{mg}$. At the end of surgery, all patients were reversed with iv neostigmine $(40-70 \mu \mathrm{g} / \mathrm{kg})$ and iv glycopyrrolate $(7-15 \mu \mathrm{g} / \mathrm{kg})$ titrated to clinical effect. Extubation was done when standard criteria for extubation were fulfilled. After emerging from anaesthesia, the patients were assessed for pain, nausea and vomiting. Thereafter patients were transferred to the recovery room for the first 24 hours. The pain was assessed on $10 \mathrm{~cm}$. VAS scale where $0=$ no pain and 10=worse imaginable pain. The data were collected at 2, 4, 6, 9, 12, 18 and 24 hours. Injection fentanyl as analgesic was given when VAS scores $\geq 4$ in the dosage of $25 \mu \mathrm{g}$ iv every 10 min until VAS score for pain becomes 3 or less (dose not exceeding $300 \mathrm{mcg}$ in 3 hours). Patients not responding to the above treatment were excluded from the study with intent to treat. Number of patients experiencing PONV were accounted for and patients having nausea for $>10$ mins and vomiting were given inj. ondansetron $(0.1 \mathrm{mg} / \mathrm{kg})$ iv. The total dose of administered fentanyl during the first 24hour period was recorded. Time to the first analgesic requirement was also noted and considered as duration of 
postoperative analgesia. VAS score at first analgesic requirement was also noted. The number of patients experiencing nausea and vomiting and total amount of ondansetron received in first 24 hours were also recorded. Postoperative heart rate, mean arterial pressure (MAP) and peripheral oxygen saturation (SpO2) were monitored continually in the recovery room and recorded at 1hour intervals. Apart from these, patients were monitored throughout the study period for any complication.

\section{Result}

One hundred and thirty-eight patients were assessed for eligibility. Twenty-nine patients did not meet the inclusion criteria and 37 patients decided against joining the study. So, 72 patients were taken up for randomization into two groups of 36 each to receive thoracic paravertebral block either with ropivacaine or bupivacaine. There were no refusals after randomization. So, data from 72 patients were available for analysis; group $R(n=36)$, group $B(n=36)$.

Table 1 Demographic Parameters

\begin{tabular}{|l|c|c|c|}
\hline Parameters & Group R (n=36) & Group B (n=36) & P value \\
\hline Age (years) & $44.72 \pm 8.133$ & $46.19 \quad \pm 8.783$ & $0.463(\mathrm{NS})$ \\
\hline Weight $(\mathrm{kg})$ & $51.19 \pm 4.904$ & $52.53 \quad \pm 4.861$ & $0.251(\mathrm{NS})$ \\
\hline Height $(\mathrm{cms})$ & $152.69 \pm 3.733$ & $22.06 \pm 1.359$ & $0.117(\mathrm{NS})$ \\
\hline BMI $(\mathrm{kg} / \mathrm{m} 2)$ & $21.94 \pm 1.797$ & $26(72) / 10(28)$ & $0.609(\mathrm{NS})$ \\
\hline ASA status (I/II) & $24(67) / 12(33)$ & $92.14 \pm 6.586$ & $0.143(\mathrm{NS}$ \\
\hline $\begin{array}{l}\text { Duration of } \\
\text { surgery(mins) }\end{array}$ & $94.50 \pm 6.918$ & & \\
\hline
\end{tabular}

Data are given as mean $\quad \mathrm{SD}, \mathrm{n}(\%)$. Test done: Independent sample t-test, Pearson chi square.

$\mathrm{NS}=$ non significant.

Table 2 Types of Surgeries

\begin{tabular}{|l|lc|cc|c|}
\hline Type of Surgery & \multicolumn{2}{|c|}{ Group R (n=36) } & \multicolumn{2}{|c|}{ Group B (n=36) } & P value \\
\hline Simple mastectomy & 08 & $(22.2 \%)$ & 06 & $(16.7 \%)$ & $>0.05(\mathrm{NS})$ \\
\hline Toilet mastectomy & 01 & $(2.8 \%)$ & 02 & $(5.5 \%)$ & $>0.05(\mathrm{NS})$ \\
\hline $\begin{array}{l}\text { Modified radical } \\
\text { mastectomy }\end{array}$ & 21 & $(58.3 \%)$ & 19 & $(52.8 \%)$ & $>0.05(\mathrm{NS})$ \\
\hline $\begin{array}{l}\text { Modified radical } \\
\text { mastectomy with } \\
\text { axillary lymph node } \\
\text { dissection }\end{array}$ & 06 & $(16.7 \%)$ & 09 & $(25 \%)$ & $>0.05(\mathrm{NS})$ \\
\hline
\end{tabular}

Data are presented as $n(\%)$. Test done: Pearson Chi-square. NS= non significant.

Table 3 Visual Analogue Scale (VAS) Scores for Postoperative Pain

\begin{tabular}{|l|c|c|c|}
\hline Parameters & Group R (n=36) & Group B (n=36) & P value \\
\hline VAS in immediate postoperative period & $0.17 \pm 0.378$ & $0.22 \pm 0.422$ & $0.558(\mathrm{NS})$ \\
\hline VAS at 2 hrs & $0.22 \pm 0.422$ & $0.36 \pm 0.487$ & $0.200(\mathrm{NS})$ \\
\hline
\end{tabular}




\begin{tabular}{|l|c|c|c|}
\hline VAS at 4 hrs & $0.67 \pm 0.676$ & $0.92 \pm 0.732$ & $0.137(\mathrm{NS})$ \\
\hline VAS at 6 hrs & $1.28 \pm 0.779$ & $1.56 \pm 0.504$ & $0.077(\mathrm{NS})$ \\
\hline VAS at 9 hrs & $2.03 \pm 0.560$ & $2.53 \pm 0.696$ & $0.001^{*}$ \\
\hline VAS at $12 \mathrm{hrs}$ & $2.97 \pm 0.654$ & $2.94 \pm 0.532$ & $0.844(\mathrm{NS})$ \\
\hline VAS at $18 \mathrm{hrs}$ & $2.03 \pm 0.506$ & $2.72 \pm 0.659$ & $0.000^{*}$ \\
\hline VAS at $24 \mathrm{hrs}$ & $2.08 \pm 0.692$ & $2.78 \pm 0.422$ & $0.000^{*}$ \\
\hline VAS at 1 st analgesic & $4.67 \pm 0.632$ & $4.86 \pm 0.723$ & $0.229(\mathrm{NS})$ \\
\hline Maximum VAS in $24 \mathrm{hrs}$ & $4.83 \pm 0.609$ & $4.89 \pm 0.708$ & $0.722(\mathrm{NS})$ \\
\hline
\end{tabular}

Data are given as mean SD. Test done: Independent sample t-test. $(*=$ Statistically significant; $\mathrm{NS}=$ nonsignificant).

Table 4 Thoracic Paravertebral Block Characteristics

\begin{tabular}{|l|c|c|c|}
\hline Parameters & Group R (n=36) & Group B (n=36) & P value \\
\hline Number of dermatomes blocked & $6.53 \pm 0.736$ & $6.36 \pm 0.867$ & 0.382 (NS) \\
\hline Time to surgical anaesthesia (min) & $15.72 \pm 2.721$ & $21.28 \pm 3.762$ & $0.000^{*}$ \\
\hline Time to first analgesic requirement. (Mins) & $646.56 \pm 115.85$ & $609.25 \pm 75.02$ & 0.109 (NS) \\
\hline
\end{tabular}

Data are given as mean SD. Test done: Independent sample t-test. $(*=$ statistically significant; NS= nonsignificant $)$

Demographic data was comparable in both the groups as seen in table no.1.Intraoperative vital parameters which included the pulse rate, mean arterial pressure and $\mathrm{SpO} 2$ showed insignificant difference between both the groups.

Mean requirement of fentanyl in the first 24 hours were $68.06 \pm 23.61 \mu \mathrm{g}$ for the $\mathrm{R}$ group as compared to $76.39 \pm 17.87 \mu \mathrm{g}$ for the $\mathrm{B}$ group which was statistically insignificant $(p=0.096)$. Table 4 shows that the time to request for the first analgesic in the postoperative period was $646.56 \pm 115.85 \mathrm{mins}$ in the group $\mathrm{R}$ and $609.25 \pm 75.02$ mins for the group B. Though this apparently shows the difference it is statistically insignificant $(p=0.11)$. However it was found that some patients in group $\mathrm{R}$ had sufficient analgesia even after 24 hours. Time to first request of analgesic requirement /duration of analgesia was $15.72 \pm 2.721$ mins. in group $\mathrm{R}$ and $21.28 \pm 3.762$ mins $(\mathrm{P}=0.000)$ which is statistically significant.

\section{Discussion}

The present study shows that the onset of surgical anaesthesia was significantly earlier with ropivacaine $(15.72 \pm 2.72$ mins $)$ than with bupivacaine (21.28 $\pm 3.76 \mathrm{mins})$. Although the duration of postoperative analgesia was comparable the VAS scores in the later postoperative period $(9,18$ and 24 hours) were significantly less in patients receiving TPVB with ropivacaine.

Both single and multiple PVB injections were used for open inguinal hernia repair.

Simple mastectomy, toilet mastectomy, modified radical mastectomy with or without axillary clearance were included in the study. A minimum of 5 dermatomes from T2-T6 were blocked and considered to be surgically acceptable. PVB was performed with single injection technique. Acceptable surgical conditions for breast surgery can be with single injection PVB have been 
accomplished. ${ }^{9,10}$ Terheggen MA and colleagues ${ }^{11}$ used a single level continuous thoracic PVB by placing a catheter at T3-T4 inter space for minor breast surgeries as they concluded that a single level PVB reduced patient discomfort and chances of pneumothorax that can be caused by multiple injection technique. Mean time to a complete loss of sensation to pinprick of the targeted dermatomes, was $21.28 \pm 3.762$ minutes in group B which is significantly higher than group $\mathrm{R}(15.72 \pm 2.721$ minutes $)(\mathrm{p}<0.000)$. This finding corroborates with the results obtained by Bertini and colleagues ${ }^{12}$ in axillary brachial plexus block, and Hura $G$ and colleagues ${ }^{8}$ in TPVB. Average number of dermatomes blocked in group $\mathrm{R}$ was $6.53 \pm 0.736$ which was comparable with group B, 6.36 \pm 0.867 . Highest and lowest dermatomes blocked were being $\mathrm{T} 1$ and $\mathrm{T} 8$ respectively in both the groups. This finding corresponds with studies by Cheema and colleagues ${ }^{13}$ who noted a unilateral spread of sensory analgesia from one to eight dermatomes after a single injection of $15 \mathrm{ml} 0.5 \%$ bupivacaine for thoracic PVB. The present study found a tendency of the block to traverse more in caudad direction. Similar tendency of caudal spread was observed by Naja ZM and colleagues. ${ }^{14}$ Postoperative pain can have a significant effect on patient recovery. Despite an increased focus on pain management programs and the development of new standards for pain management, many patients continue to experience intense pain after surgery. Jeffrey L. Apfelbaum and colleagues in their study found that approximately $80 \%$ Of patients experienced acute pain after surgery. ${ }^{15}$ Of these patients, $86 \%$ had moderate, severe, or extreme pain, with more patients experiencing pain after discharge than before discharge. In our study, control of postoperative pain was one of the principal concerns. The means to assess postoperative pain control was the total amount of analgesic consumed in the first 24 hour period after surgery, the time to first analgesic consumption and also the visual analogue scale (VAS) scores at different times. The results in terms of postoperative pain relief, the duration and the intensity were comparable and there was no significant difference between both the group however it was seen that after $24 \mathrm{hrs}$. some patients had sufficient analgesia. This longer duration of blockade may be due to a better penetration of ropivacaine to the second intercostal nerve supplying T2 dermatome as opined by Hura $\mathrm{G}$ et al. ${ }^{8}$ Ropivacaine is known to have vasoconstrictive properties ${ }^{16}$ and may cause relative ischaemia of the structures on the paravertebral space, because this space is not very well vascularized. ${ }^{17}$ This may further slow down elimination of ropivacaine (reduction of washout). ${ }^{17}$ Apart from this, ropivacaine is less lipid soluble than bupivacaine ${ }^{18}$, so it may better penetrate to the nerve fibres and stay longer in the paravertebral space. Ropivacaine is known to produce a shorter sensory blockade than bupivacaine, when given epidurally. ${ }^{19}$ In the epidural space with the rich blood supply and rapid washout, the situation may be totally different. Low solubility of ropivacaine in fatty tissue $^{20}$ translates into its more rapid washout from the epidural space, and this is probably responsible for a shorter duration of epidural blockade after ropivacaine. Vasoconstrictive properties of ropivacaine may not counteract the rich blood supply of the epidural space. On the contrary, the same vasoconstrictive properties of ropivacaine may explain the sensory blockade beyond 24 hrs. as noted in our study. Our result can be supported by Hura $\mathrm{G}$ and colleagues ${ }^{8}$ who found significant dermatomal blockade in ropivacaine group to perform another surgery after 24 hrs. Kairaluoma PM and colleagues ${ }^{21}$ studied the effect of single-injection paravertebral block before general anaesthesia on postoperative pain and postoperative nausea and vomiting (PONV) after breast surgery and found that patients given PVB with bupivacaine had less postoperative pain, as indicated by longer times to first analgesic dose, lower VAS scores, and $40 \%$ smaller oxycodone consumption in the PACU. PVB 
reduced the opioid demand statistically significantly $(P<0.05)$.

So, the results of the present study shows that thoracic PVB provides better postoperative analgesia after breast surgery with either of the two drugs indicated by longer time to requirement of first postoperative analgesic, which corroborates with previous studies as well. ${ }^{22}$ Studies by Terheggen and colleagues ${ }^{11}$, Naja and colleagues $^{14}$, Coveney and colleagues ${ }^{23}$ and Moller and colleagues ${ }^{22}$ have reported significant reduction of pain scores only in the early postoperative period with PVB. Again studies by Hura $G$ and colleagues ${ }^{8}$, Kairaluoma and colleagues $^{21}$, Klein and colleagues ${ }^{24}$ showed significant reduction in pain score up to 24 hours, which correlates with findings of our study.

\section{Conclusion}

Thus, it can be concluded from our study that both bupivacaine and ropivacaine given as a single injection paravertebral block in oncologic breast surgeries provide excellent postoperative analgesia, although ropivacaine is slightly superior to bupivacaine in achieving faster sensory blockade while also regressing more slowly in comparison to bupivacaine.

\section{References}

1. Poleshuck EL, Katz J, Andrus CH, Hogan LA, Jung BF, Kulick DI, et al. Risk factors for chronic pain following breast cancer surgery: a prospective study. J Pain 2006; 7: 626-34.

2. Greengrass $\mathrm{R}$, O`Brien F, Lyerly $\mathrm{K}$, Hardman D, Gleason D, D‘Ercole F, et al. Paravertebral block for breast cancer surgery. Can J Anaesth 1996;43:858-61.

3. Gartner R, Jensen MB, Nielsen J, Ewertz M, Kroman N and Kehlet H. Prevalence of and factors associated with persistent pain following breast cancer surgery. J Am Med Assoc 2009; 302: 1985-92.

4. D‘Ercole FJ, Scott D, Bell E, Klein SM, Greengrass RA. Paravertebral blockade for modified radical mastectomy in a pregnant patient. AnesthAnalg 1999; 88:1351-3.

5. Buckenmaier III CC, Steele SM, Nielsen KC, Klein SM. Paravertebral somatic nerve blocks for breast surgery in a patient with hypertrophic obstructive cardiomyopathy. Can J Anaesth 2002; 49: 571-4.

6. Buckenmaier III CC, Steele SM, Nielsen KC, Martin AH, Klein SM. Bilateral continuous paravertebral catheters for reduction mammoplasty. Acta AnaesthesiolScand 2002; 46: 1042-5.

7. Najarian MM, Johnson JM, Landercasper J, Havlik P, Lambert PJ, McCarthy D. Paravertebral block: an alternative to general anesthesia in breast cancer surgery. Am Surg 2003; 69: 213-8.

8. Hura G, Knapik P, Misiolek H, Krakus A, Kare J, et al. Sensory blockade after thoracic paravertebral injection of ropivacaine or bupivacaine. Eur J Anaesthesiol 2006;23: 658-64.

9. Naja MZ, Ziade MF, Lonnqvist PA. Nerve-stimulator guided paravertebral blockade vs. general anaesthesia for breast surgery: a prospective randomized trial. Eur J Anaesthesiol 2003;20:897-903.

10. Pusch F, Freitag H, Weinstabl C, Obwegeser R, Huber E, Wildling E. Single-injection paravertebral block compared to general anaesthesia in breast surgery. Acta Anaesthesiol Scand 1999; 43: $770-4$.

11. Terheggen MA, Wille F, Rinkes IHB, Ionescu TI, Knape JT. Paravertebral blockade for minor breast surgery. AnesthAnalg 2002; 94: 335-9.

12. Bertini L, Tagariello V, Mancini S et al. $0.75 \%$ and $0.5 \%$ ropivacaine for axillary brachial plexus block: a clinical comparison with $0.5 \%$ bupivacaine. Region Anesth Pain Med 1999; 24: 514-8.

13. Cheema SP, Ilsley D, Richardson J, Sabanathan S. A thermographic study of 
paravertebral analgesia. Anaesthesia 1995; 50: 118-21.

14. Naja ZM, El-Rajab M, Al-Tannir MA, Ziade FM, Tayara K, Younes $\mathrm{F}$ et al. Thoracic paravertebral block: influence of the number of injections. Reg Anesth Pain Med 2006; 31: 196-201.

15. Apfelbaum JL, Chen C, Mehta SS and Gan TJ. Postoperative Pain Experience: Results from a National Survey Suggest Postoperative Pain Continues to $\mathrm{Be}$ Undermanaged. AnesthAnalg 2003; 97: 534-40.

16. McClellan KJ, Faulds D. Ropivacaine: an update of its use in regional anaesthesia. Drugs 2000; 60: 1065-93.

17. Richardson J. Paravertebral and intercostal nerve blocks. In: Narrinder R, ed. Highlights in Regional Anaesthesia and Pain Therapy, Vol. X. Limassol, Cyprus: Cyprint Ltd, 2001:113-20.

18. Wang RD, Dangler LA, Greengrass RA. Update on ropivacaine. Expert OpinPharmacother 2001; 2: 2051-63.

19. Brown DL, Carpenter RL, Thompson GE. Comparison of $0.5 \%$ ropivacaine and $0.5 \%$ bupivacaine for epidural anesthesia in patients undergoing lower-extremity surgery. Anesthesiology 1990; 72: 633-6.

20. Akerman B, Hellberg IB, Trossvik C. Primary evaluation of the local anaesthetic properties of the amino amide agent ropivacaine (LEA 103). Acta Anaesthesiol Scand 1988; 32: 571-8.

21. Kairaluoma PM, Bachmann MS, Korpinen AK, Rosenberg PH, Pere PJ. Singleinjectionparavertebral block before general anaesthesia enhances analgesia after breast cancer surgery with and without associated lymph node biopsy. AnesthAnalg 2004; 99: $1837-43$.

22. Moller JF, Nikolajsen L, Rodt SA, Ronning H, Carlsson PS. Thoracic Paravertebral Block for Breast Cancer
Surgery: A Randomized DoubleBlind Study. AnesthAnalg 2007; 105: $1848-51$.

23. Coveney E, Weltz CR, Greengrass R, Iglehart JD, Leight GS, Steele SM, et al. Use of paravertebral block anesthesia in the surgical management of breast cancer: Experience in 156 Cases. Ann Surg. 1998;227:496-501.

24. Klein SM, Bergh A, Steele SM, Georgiade GS, Greengrass RA. Thoracic paravertebral block for breast surgery. AnesthAnalg 2000; 90: 1402-5. 